\title{
A Conversation about Livingstone Online and the Victorian Record of African Exploration
}

\author{
Kate Simpson, Justin D. Livingstone, and Adrian S. Wisnicki
}

Livingstone Online is a digital museum and library that provides a global audience with public access to the vast written and visual legacies of David Livingstone (1813-1873), the British Victorian explorer of Africa. The site's manuscripts span Livingstone's adult life, ranging from family correspondence written in the 1830 s, to the field diaries of the 1870 os composed in the Congo Basin. Additional illustrations, photographs, and other materials encompass nearly two centuries of relevant historical and contemporary sources. Over the course of Livingstone Online's fifteen-year development, the project has made significant contributions to scholarly conversations and public knowledge about British imperial history and African history, and has become a leader in the field in developing best practices for the digitization and digital publication of manuscript material and images from the 'global south'.

Livingstone Online was founded in 2004 by Christopher Lawrence (now Professor Emeritus, University College London) with support from the Wellcome Trust. The site originally published letters featuring medical and scientific content, with the initial aim of examining the connections between western medicine and the European projects of exploration, imperialism, and colonization. Having originated as an initiative in the medical humanities, the remit of Livingstone Online under the directorship of Adrian S. Wisnicki (University of Nebraska-Lincoln) has subsequently evolved and expanded to cover a much wider range of manuscripts and illustrations related to Livingstone's life and expeditions, his long-term memorialization, and the preservation of his written and visual legacies by others. The new phase began in 2013 with the Livingstone Online Enrichment and Access Project (LEAP), funded by the National Endowment for the Humanities (USA). This major four-year initiative set out to redevelop the site, grow its digital collection, and ensure the standardization and long-term preservation of its core data. By partnering with nearly fifty archival institutions to date, Livingstone Online is today the largest online repository related to any historical British traveller in Africa (Fig. 1).

This extensive digital museum and archive now also supports different forms of scholarship: by collating documents held in institutions across the globe, Livingstone Online provides a digital resource for work on the 


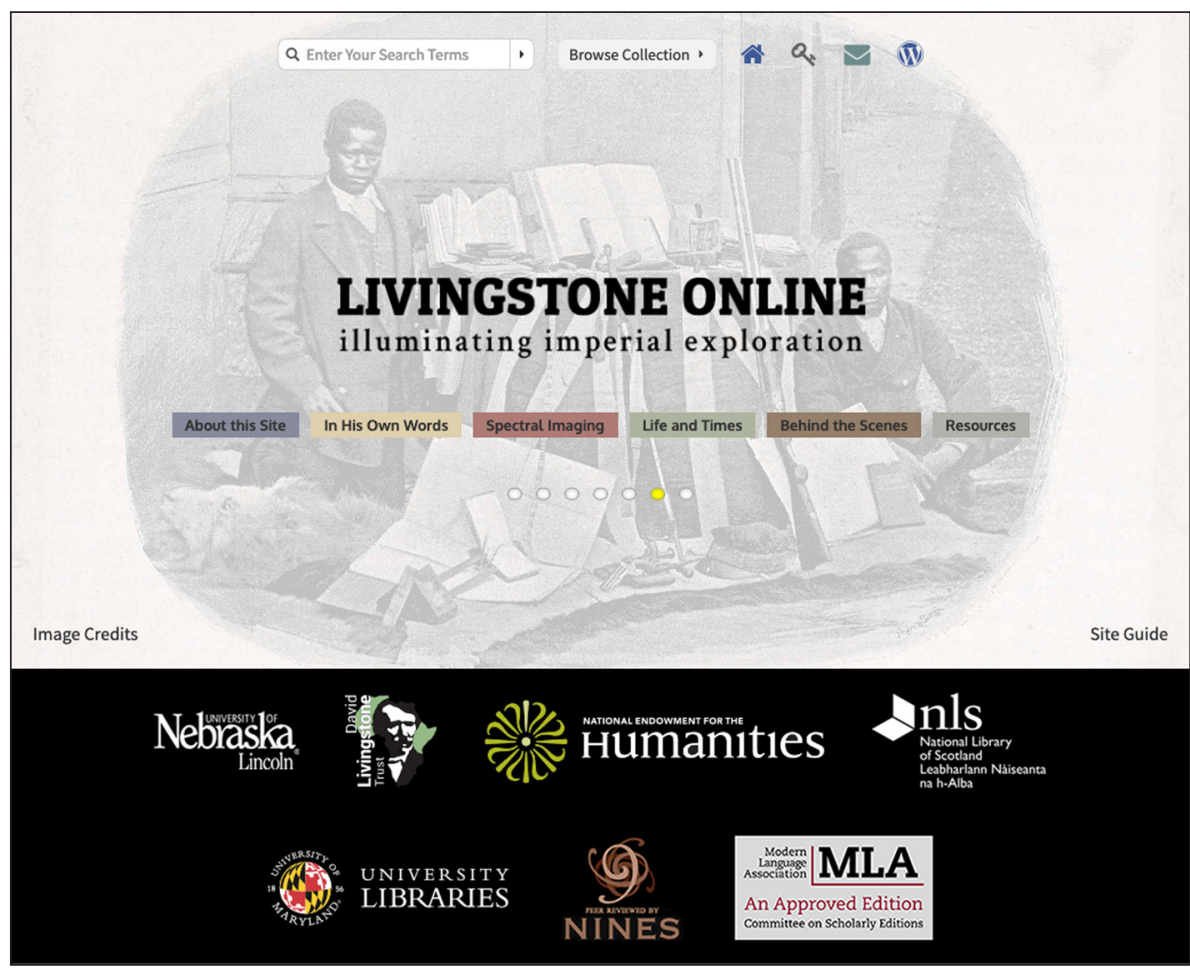

Fig. 1: David Livingstone's followers, Susi and Chuma, pictured with his former possessions, 1873. (C) Wellcome Library, London CC BY 4.0. This screenshot shows the homepage for Livingstone Online.

reconstruction of African history, the Victorian missionary movement, the development of tropical medicine, the 'prelude' to the Scramble for Africa, the practices of geographical exploration, the production of expeditionary records, and the construction of imperial knowledge. Livingstone Online, moreover, contributes to scholarship by providing a wide assortment of its own critical materials; these situate Livingstone in both western and nonwestern historical and cultural contexts. Through essays and theoretical reflections, the site makes particular effort to foreground the African contexts of Livingstone's journeys, the intercultural nature of expeditionary travel, and the editorial processes by which Livingstone's manuscripts have been circulated and preserved. In this respect, the site is particularly rich in documentation related to the development of Livingstone Online itself, including detailed project histories that take users into the inner workings of the project via text, image, and project documents.

Livingstone spent approximately three decades in Africa - a longer period of residence than any other contemporary European explorer and travelled across vast portions of the continent. In three extended visits $\left(1841-56,185^{8}-64,1866-73\right)$, he journeyed through many regions including 
present-day South Africa, Botswana, Zambia, Angola, Democratic Republic of Congo, Tanzania, Malawi, and Mozambique. By writing prolifically throughout his travels, Livingstone produced one of the most substantial eyewitness accounts of central and southern Africa in the nineteenth century. Often these works are the only written records related to a variety of African communities for the periods in question. His record is wideranging in scope, incorporating geographical, scientific, and environmental observations, as well as commentary on the politics, social organization, and cultural practices of numerous African ethnic groups. Livingstone's writings, moreover, reward the detailed study of British imperial history because they contributed to the enormous escalation of interest in Africa in the final decades of the Victorian era. The circulation of his publications and correspondence in Britain inspired expeditions and missions, incited commercial interest in central African resources, and participated in promoting colonial intervention.

Livingstone Online renews scholarship on the explorer's extensive corpus by hosting some 15,000 high-resolution manuscript images alongside critically edited transcriptions totalling nearly 7500 pages, and by publishing numerous detailed essays and other critical interventions by the academics who make up the project team. A key facet of the site's scholarly contribution is its portfolio of critical editions, which address manuscripts from across Livingstone's career and incorporate many sets of individual transcriptions. To date the site has published five digital scholarly editions: Livingstone's 1871 Field Diary (2012-13, 2017), Livingstone's 1870 Field Diary (2017, 2019), Livingstone's Manuscripts in South Africa (1843-1872) (2018), Livingstone's Final Manuscripts (1865-1873) (2018), and Livingstone's Missionary Travels Manuscript (1857) (2019). The first two apply advanced spectral imaging technology to examine damaged field documents, while the latter three investigate manuscripts and manuscript collections of particular significance. Several of these, plus the site as a whole, have received the prestigious Seal of the Modern Language Association (MLA) signifying an Edition Approved by the Committee on Scholarly Editions. Taken together, the editions complement the numerous other critical materials on the site to undertake a comprehensive reconsideration of one of the most iconic explorers and imperial heroes of the nineteenth century and to critically frame the ways in which users encounter Livingstone's complex written and visual legacies in the present day. In doing so, the site considerably extends scholarship on the European project of geographical exploration, the documentation of expeditionary travel and intercultural encounter, and the Victorian imagination of central and southern Africa.

In February 2020 three members of the project team gathered online to discuss the site's latest edition - Livingstone's Missionary Travels Manuscript (1857) - and the wider development of Livingstone Online as a nineteenth-century digital humanities project over the last decade and 
a half. The conversation evolved in stages, with members first discussing the early years of Livingstone Online and the steps that led them to join the team, then turning to their work in developing the site and the challenges that arose, and finally, reflecting on their experiences overall and key lessons learned. Adrian Wisnicki, as noted above, is the director of Livingstone Online; Kate Simpson (University of Glasgow) is an Associate Project Scholar who has contributed to each of the site's critical editions; and Justin Livingstone (Queen's University Belfast) is the joint director (with Wisnicki) of Livingstone's Missionary Travels Manuscript (1857).

\section{The early years of Livingstone Online}

Justin: Shall we begin by talking a little about our backgrounds before our involvement in Livingstone Online and the digital humanities [DH]? Adrian, what were you working on before you began to direct Livingstone Online?

Adrian: To start, nothing at all related to the digital humanities, David Livingstone, or British imperialism in Africa. My PhD dissertation, which I completed in the early 2000 s, set out to explore the culture of conspiracy in the Victorian novel and relied on a very traditional analytical and theoretical interpretive framework. However, in 2003, I followed my future wife to Botswana where she took up legal work related to a year-long Fulbright, while I began working part-time for ACHAP [African Comprehensive HIV/AIDS Partnerships], an initiative funded by Merck and the Bill and Melinda Gates Foundation. Neither my wife nor I had any experience with Africa at that point, and I, as a scholar of literature, had not even read the most foundational of African literary works, such as Chinua Achebe's Things Fall Apart. However, the goal of our year abroad was to push ourselves in new directions. And that we did. We had an amazing experience immersing ourselves in a culture that was not our own, while, as luck would have it, I found a local bookstore that carried numerous works from the African Writers Series. So, in that year, I read some thirty to forty works in the series. Through this process, I discovered that not only was I interested in African literature, history, and colonialism, but that I wanted to extend my research in that direction. That led to a new book project, Fieldwork of Empire, which I began around 2005. ${ }^{1}$ The project examined the influence of local African contexts on the production of Victorian-era narratives of travel and exploration by the likes of Livingstone, Burton, Speke, Stanley, etc. - in other words, the usual suspects. However, what came to distinguish the project as a critical intervention, especially as it evolved over the next few years, was its methodological approach. I found that I was little

${ }^{1}$ Adrian S. Wisnicki, Fieldwork of Empire, 1840-19o0: Intercultural Dynamics in the Production of British Expeditionary Literature (New York: Routledge, 2019). 
interested in the biographies of the explorers, but fascinated in investigating the influence on British narratives of the African communities among which the explorers travelled.

Kate: So given your background as a Victorianist and your developing interest in British exploration as well as African culture and history, what was it that led you into the digital humanities?

Adrian: By 2009 I had made it to chapter four of the book and was developing a detailed economic history of a small village in central Congo called Nyangwe. This village and some of the events that happened there, as I would later argue, came to have a major influence on subsequent British representations of Africa as a whole. The village had been visited in the 1870 os by Livingstone, Stanley, and Cameron, followed by a host of other European travellers in subsequent decades. Over the course of the latter half of the nineteenth century, the village also became a significant depot for Arab traders. Finally, the village was the site of a major regional African market. These factors combined to make the village an intriguing entity. Understanding the on-the-ground circumstances of intercultural encounter in this location, I believed, would illuminate larger patterns of such interaction in this part of Africa during that period.

Justin: Am I right in thinking that it was also at this stage that you were reading the work of Roy Bridges?

Adrian: That's right. In about 2005 or 2006 , I first encountered a series of essays by Bridges in which he argues for the importance of original manuscripts produced by British explorers in the field. Such manuscripts are often less edited than their latter published counterparts and contain field-based data in raw form, including many bits that would be revised or erased all together in the publication process. So, under the influence of Bridges's work, I sought out the relevant manuscripts by Livingstone, Cameron, Stanley, and others one by one. When I came to Livingstone's 1871 Field Diary, however, I hit a major snag. Livingstone had written the diary in ink made from berries over newspaper pages. By the twenty-first century, the ink had faded to the point of invisibility and was no longer legible with the naked eye. My attempt to read Livingstone's diary eventually led to the Livingstone Spectral Imaging Project.... The rest of the story is detailed in the critical edition of the diary published by Livingstone Online, but the short version is that I was able to partner with a set of scientists to recover the text of the diary in full by applying a type of advanced imaging technology, called spectral or multispectral imaging. And that was the project that got me started in the digital humanities, about six years after I finished my PhD (Figs. 2, 3). 


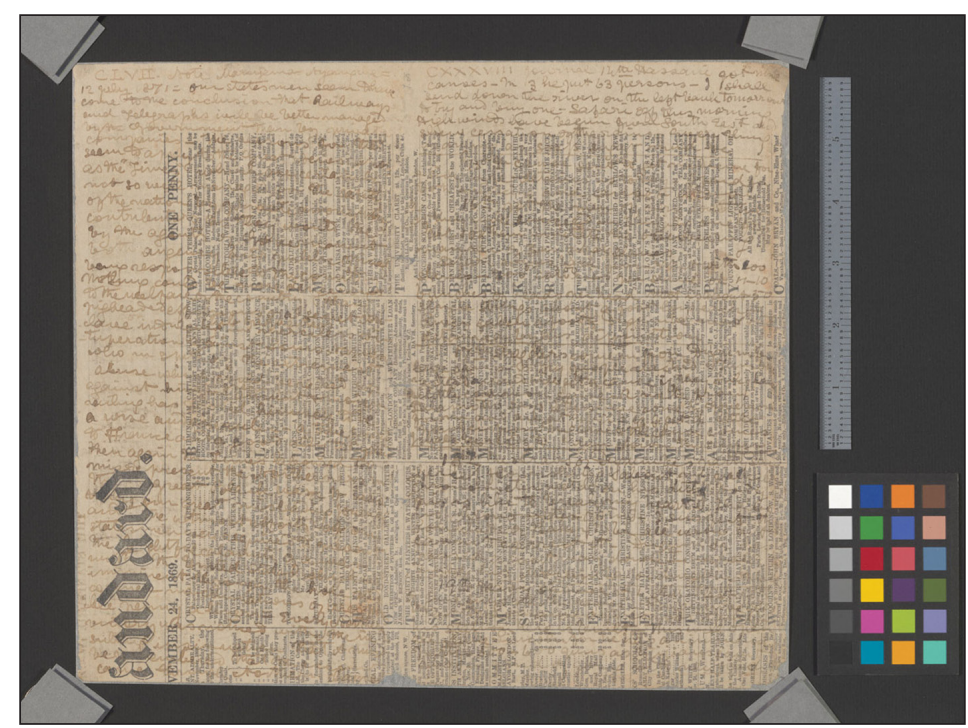

Fig. 2: See caption for Fig. 3 below.

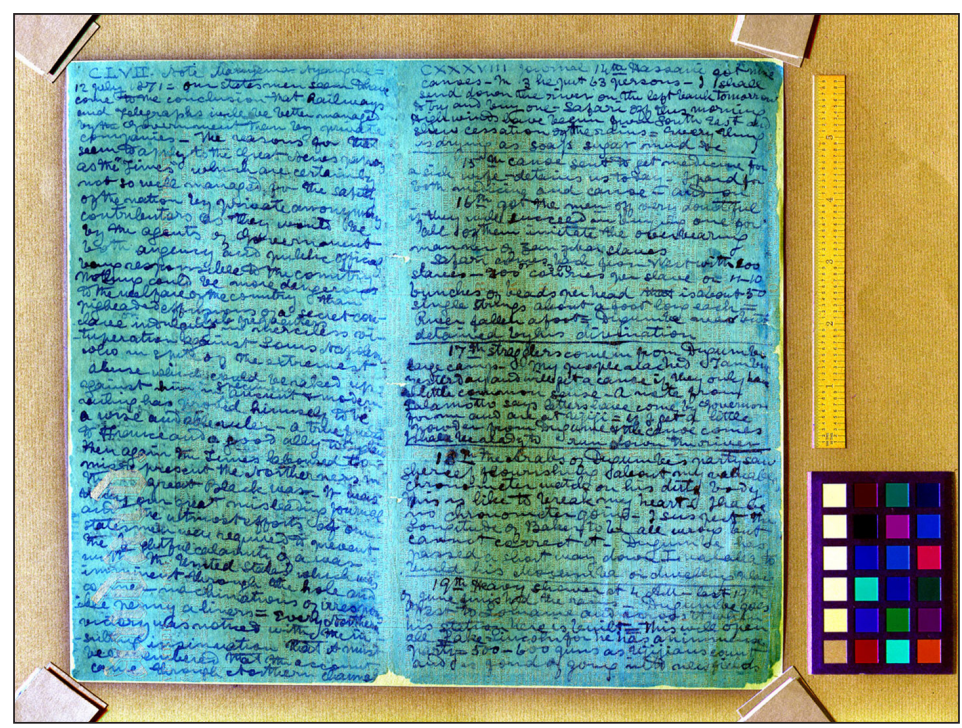

Fig. 3: Natural light (Fig. 2) and processed spectral images (Fig. 3) of two pages of the 1871 Field Diary (pp. clvii-cxxxviii). (C) David Livingstone Centre, Blantyre. As relevant, (C) Dr Neil Imray Livingstone Wilson CC BY-NC 3.o. These two images demonstrate the dramatic ability of spectral image processing to reveal diary text that is otherwise nearly invisible to the naked eye. A portion of the printed newspaper title, the Standard, is visible on the left. Note that these spectral images include a colour chart and ruler. Such items are often cropped out of illustrations but are retained in the present case in keeping with Livingstone Online's emphasis on foregrounding the various strategies by which such historical materials have been preserved and documented over time. 
Kate: So, in other words, you started working in the digital humanities by chance?

Adrian: That's right. And it was the same kind of chance that led to me joining the team of Livingstone Online. When I first began working on Livingstone's 1871 Field Diary, I had never heard of Livingstone Online. At that point, the site was under the directorship of Chris [Lawrence], who was then associated with the Wellcome Trust Centre for the History of Medicine in London. The site's focus was on digitizing letters by Livingstone that addressed medical and scientific subjects in order to examine - through one major case study - the ways in which European medicine helped facilitate scientific exploration and support colonization in Africa. I randomly came across the site one day, found that it didn't have anything of relevance to my 1871 Field Diary project, but I sent a query to Chris to see if he might have additional material not yet published on the site. At the time, I was living in London. Chris and I got into a lively email exchange, then eventually met up over a pint and hit it off. Soon thereafter I became involved in the project.

\section{Expanding the Livingstone Online team}

Justin: What about you Kate? I know you've been working in the digital humanities since the first phase of the Livingstone Spectral Imaging Project [2010-11]. How did you get interested in this area and come to start working with Adrian?

Kate: My background is closely tied in with how I became involved in the project. My PhD at Edinburgh Napier University was on imperial adventure romance writer H. Rider Haggard and his early twentieth-century trilogy, Zikali. The history that Haggard wrote about in the trilogy was neither collusive nor consensual with the Zulu, who were the focus of these novels. He wrote a complex colonial narrative that characterized the Zulu as a proud and mythic, yet ultimately doomed, people. The Zikali trilogy, Marie, Child of Storm, and Finished, narrated three pivotal events in the nineteenth-century history of the Zulu people. In the books Haggard promoted the primacy of the Englishman in nineteenth-century southern African historiography, while also aggrandizing the Zulu kingdom. This reframing of indigenous history to suit a colonial narrative would be evidence of what is a standard trope within imperial adventure romance fiction, were it not for the fact that Haggard was ambivalent in his imperialism. He thought he was recording the myths of a dying people, but he was appropriating indigenous historiographies. This refashioning of the history of the Zulu people was combined with the idea of 'great man' colonialism that Haggard took in part from his time working under Theophilus Shepstone, Director of Native Policy in Natal. Haggard would later go on to describe Shepstone 
as a surrogate father. He saw Shepstone as being emblematic of the British Empire, in which 'great authority' was left 'to the discretion of a single man' [1923]. It was in researching Haggard's sublimation of events from Shepstone's life into his fiction, specifically the 'crowning' of Cetshwayo in Finished, that I came across the artist and journalist Thomas Baines. Baines is an interesting historical figure, not least for his incredibly detailed and vivid drawings of what was Britain's colonial world, but also for his peripatetic joining of multiple colonial expeditionary groups (Fig. 4). Baines was an adjunct to Livingstone's Zambezi Expedition, and left under a reputational cloud that we now know was of Charles Livingstone's [David Livingstone's brother] doing, but my interest had been piqued. I became curious as to why these singular figures, such as Shepstone and Livingstone, were the ones that colonial and imperial narratives were crafted around. What was it about David Livingstone that encouraged people to follow him even against their own better judgement, sometimes in appalling conditions, on his travels across the continent of Africa? Luckily for me, one of my supervisors, Prof. Anne Schwan, happens to be a friend of Adrian's. So, when the team first came to spectrally image the field diaries at the National Library of Scotland in 2010 and needed a local graduate assistant to assist with data entry, it was an easy call to make.

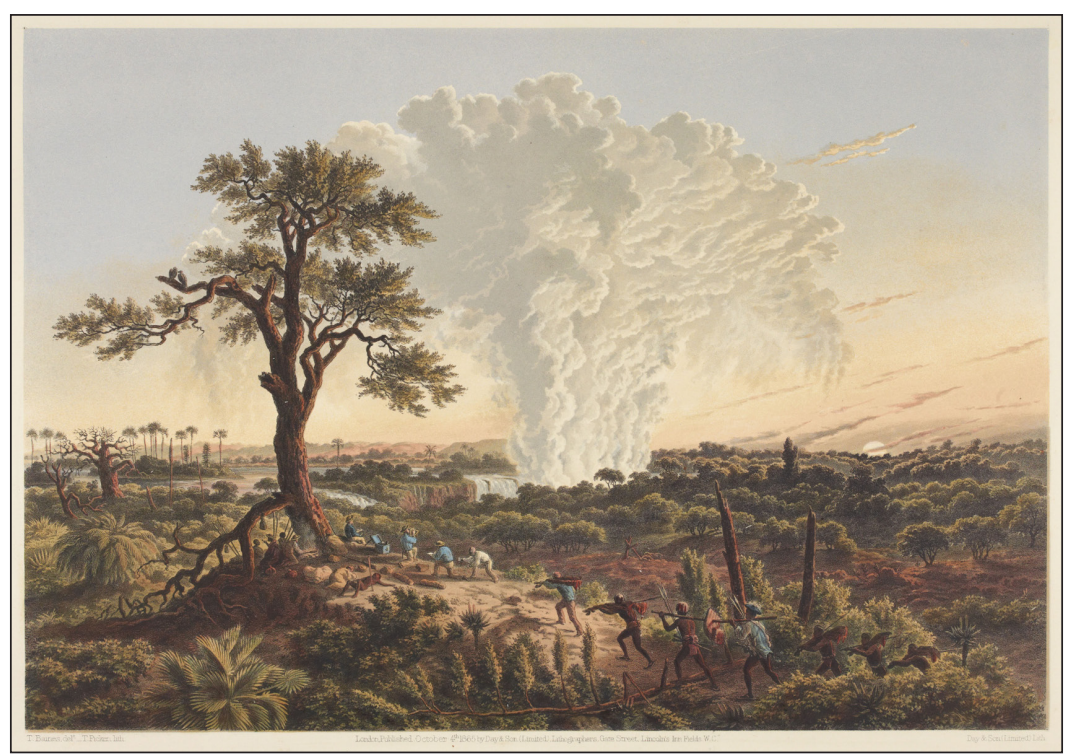

Fig. 4: The Falls by Sunrise, with the 'Spray Cloud' Rising 1,20o feet. Illustration from Thomas Baines, The Victoria Falls, Zambesi River, Sketched on the Spot (London: Day, 1865), plate 2. (C) National Library of Scotland and Dr Neil Imray Livingstone Wilson (as relevant) CC BY-SA 2.5 UK: Scotland. In addition to publishing manuscripts, Livingstone Online makes available a wide range of historical and cultural artefacts that provide insight into nineteenth-century European representations of central and southern Africa and its local populations. 
Justin: What was it like to work with the spectral imaging team? And what sort of work did you do on the project?

Kate: Working with the spectral imaging team was the perfect learning space for a future digital humanist. The variety of people involved in the project, and the differing and different types of data that people needed or were interested in, meant that from day one I was learning how fundamental excellent communication and planning are to digital humanities projects. In particular, Mike [Toth], the programme manager, was the driving force in supporting my role in the data capture and recording process. Watching how all our different specialisms worked together and developed to produce something greater than the sum of our parts was very exciting. What was particularly interesting was that during the process of spectrally imaging the diaries, it became clear how much information had been previously lost or was unreadable and thus not in the published texts. I became aware that the history I thought I knew of Livingstone was actually a lot more complex and equivocal. I wanted to try to understand the nature of the journeys Livingstone took. Once the team had gone back to America, I continued to work remotely with Adrian and the team to transcribe the diary in TEI, and I also began to develop a schools' outreach framework. Subsequently, when Adrian and Megan [Ward] got the NEH Humanities Collections and Reference Resources Grant, I was able to keep working on the project in the transcription and encoding of further letters, field diaries, and journals. How about you Justin?

Justin: Like you, I was writing my PhD when I first came across both Livingstone Online and the spectral imaging project. In fact, for my thesis I was actually working on Livingstone - or rather, on his posthumous reputation. Livingstone is probably one of the most written about figures of the nineteenth century; since his death in 1873 he has been the subject of hundreds of popular books and biographical studies. What I became interested in was the mythology surrounding Livingstone, or what has been described as his cultural 'afterlife'. Drawing on a methodology initially developed by Nicolaas Rupke, an historian of science, I set out to write a metabiography - or a biography of biographies - that would disclose the ways in which Livingstone has been written and rewritten, imagined and reimagined, for different purposes from the late nineteenth century to the present. ${ }^{2}$ Metabiography foregrounds the malleability of historical reputations by investigating the ways in which biographical representations are intimately connected to contemporary sociopolitics. My thesis, which later became a monograph, was particularly concerned to trace Livingstone's

${ }^{2}$ Justin D. Livingstone, Livingstone's 'Lives': A Metabiography of a Victorian Icon (Manchester: Manchester University Press, 2014). 
status as an icon of empire who was used on behalf of the imperial project until at least the mid-twentieth century. It followed Livingstone's changing reputation across the Scramble for Africa, the Edwardian empire, and post-WWI trusteeship, through to late-colonial initiatives such as 'partnership' and the Central African Federation. But in working on Livingstone's cultural afterlife, I was naturally also interested in the ways in which Livingstone represented himself in his many writings and particularly in his major travelogue, Missionary Travels. ${ }^{3}$ In what ways, I wondered, did Livingstone's self-representation contribute to his later reputation? It was at this point, in around 2010, that I came across the Livingstone Online site which had already digitized and transcribed a portion of the letters that I wanted to consult.

Kate: So how did things transpire from there? How did your work on Livingstone lead you to become interested in digital research?

Justin: Well, in encountering Livingstone Online I was struck by the possibilities that digital technologies have for creating open access archives, free at the point of use, which allow the consultation of material that might otherwise be spread across the globe. But it was really learning about the spectral imaging project that convinced me that I wanted to engage more fully with scholarship in the digital humanities. In 2010 - by sheer chance $-\mathrm{a}$ friend told me about the launch of the 1871 Field Diary project in the National Library of Scotland, and I went along to that. The results of applying imaging technology to a palimpsest document were incredibly impressive. It was remarkable to see the recovery of text that couldn't be read with the naked eye and which might have been indecipherable since the late nineteenth century. Although my own work has never involved spectral imaging, the 1871 Field Diary highlighted for me the scope that the digital humanities offer for engagement with the materiality of archival documents. In the course of my research, I'd spent quite a bit of time working on Livingstone's handwritten manuscript of Missionary Travels, which contains passages of commentary that never appeared in the published text. ${ }^{4}$ I began to realize that the intermediate status of this document lying between in-field records and published narrative, though closer to the latter - made it one of considerable significance for understanding the production of Victorian works of travel. After the lecture at the National

3 David Livingstone, Missionary Travels and Researches in South Africa (London: Murray, 1857).

4 David Livingstone, Missionary Travels and Researches in South Africa (Part I), Fan.Oct. 1857, Edinburgh, National Library of Scotland, MS 42428; Missionary Travels and Researches in South Africa (Part II), Jan.-Oct. 1857, MS 42429; Missionary Travels and Researches in South Africa (Part III), Jan.-Oct. 1857, MS 10702. 
Library of Scotland, I made contact with Adrian and we soon began to discuss a digital edition of the Missionary Travels manuscript. Over the next few years, as Chris [Lawrence] stepped back from Livingstone Online and Adrian took on more of a leadership role in the project, the Missionary Travels edition came into focus.

\section{Developing Livingstone Online}

Kate: Yes, we have come a long way since 2010, not only in the development of the site but in how we engage with Livingstone Online as a digital museum and library, and what that means for our own individual research. Adrian, you have been the driving force in the development of Livingstone Online. In looking back on ten years of digital scholarship, what would you say was the most difficult aspect of starting on the projects related to Livingstone Online?

Adrian: Everything! If pressed, however, I'd break things down into two categories: the complexity involved in running the projects and the contexts in which I ran the projects. When I started on the spectral imaging work, I did not have a permanent academic position. Indeed, I had gone through several temporary positions and was considering going into a different career all together. So the question I faced all the time was, should I abandon this research completely because it's a waste of time given my job prospects in the academy? This was also happening against the background of the great recession of the late 2000s, so there were years when many of the jobs for which I applied simply disappeared mid-season. However, I also met a lot of people who understood what I was doing. If their research had any kind of orbital overlap with mine, they often got drawn into the Livingstone projects. That made a huge difference in terms of my overall morale, but also made my digital work with Livingstone a key factor in keeping me in the academy as people soon began to notice my work with spectral imaging. In terms of the digital work itself, the sub answer is also everything! When I started, I was a very traditional kind of scholar, a technophobe even. So every aspect of digital humanities work was new and challenging: writing up agreements, managing teams, creating budgets, planning, spectral imaging technology, coding, developing grants, etc. But at the same time it was exhilarating because it opened up possibilities that wouldn't have existed otherwise. I discovered that I not only loved digital humanities work, but also had no fear of jumping into something about which I knew nothing because my attitude tended to default to, 'Well, here's another thing I'll have to figure out.' Most interesting and rewarding, however, were the many, many unique collaborations across disciplines that the projects created. These have now become the basis not 
only of long-term professional relationships, but also friendships, as in the case of you both.

Kate: Yes, I am certain that the friendships have been foundational to the success of the project. However, one point that might be lost on visitors to the site - when they come to it as a refined and seemingly finished entity is the amount of work it took to get there. We've been talking about how it was for you to start up in $\mathrm{DH}$, but what was it like in the middle, once you were actually developing Livingstone Online?

Adrian: Not much easier than when I started! In 2013 we received two major grants from the National Endowment for the Humanities, which had also funded the first phase of the Livingstone Spectral Imaging Project on the 1871 Field Diary. One of the grants was for the second phase on the 1870 Field Diary, the other for something called LEAP [the Livingstone Online Enrichment and Access Project]. This latter project was actually two projects masquerading as one. The first focused on redeveloping the Livingstone Online site from the ground up, the second on creating a full-scale edition of Livingstone's final manuscripts. So suddenly I went from directing one significant project to three. But clearly that wasn't enough because in those years I also managed to add the project on the Missionary Travels manuscript and yet another on Livingstone's manuscripts in South Africa, which I did with Jared McDonald who's now at the University of the Free State. To say the least, running all this was intense; I was constantly working on Livingstone Online-related material, and we had some bumps along the way. However, there were three things that considerably transformed the work. First, Megan [Ward], who's now at Oregon State, joined the project and became co-director of the site. Her contribution to running the work was immeasurable, but she also helped us rethink and rearticulate our theoretical approach to Livingstone Online as a whole. Second, the initiatives we ran concurrently might have been with different people, but they shared a common core. This frequently enabled work done on one project to help with the others. Finally, I adopted one of Livingstone's famous quotes as my own, 'I'm prepared to go anywhere, provided it be forward.' Some days were quite difficult and we progressed little, but those words helped keep everything in perspective because we were always moving forward, however incrementally. It also helped that in the midst of all this I finally landed a tenure-track position at UNL [the University of Nebraska-Lincoln].

\section{The challenges of working on Livingstone Online}

Adrian: What about you, Kate? When you first joined the team, were there aspects of the work that proved rather challenging? 
Kate: That's easy to answer. Initially, I found deciphering Livingstone's writing to be the hardest aspect of our work. I could have done with some palaeography lessons!

Justin: I can appreciate your struggle in reading Livingstone's handwriting, especially given the physical condition of the field diaries and some of his letters. I had moments of difficulty with handwriting too, although this wasn't quite such an issue in the Missionary Travels edition. The Missionary Travels manuscript certainly bears the hallmarks of a working draft, with messy additions and corrections, but it is generally more legible than the field documents. For me, the biggest challenge was the technical learning curve as I began to acquire skills in critical encoding and familiarity with the protocols of the Text Encoding Initiative [TEI]. As a literary scholar with no previous experience in any kind of coding, this was definitely the most formidable aspect of the work. I was greatly assisted, of course, by both of you and other members of Livingstone Online - and the project's customized encoding guidelines were invaluable. As time went on, I came to appreciate just how worthwhile it was to have acquired this technical competence in TEI because of the ways it enhanced close editorial work on Victorian manuscripts. For instance, we were able to capture the unique features of the Missionary Travels manuscript, such as the litany of proof correction marks, the granular details of textual deletions, additions, and overwriting, as well as the contributions of multiple hands. This encoding also provided the basis for the on-screen representations of the manuscript in transcription, which display the complexity of the book's multistage and multihand composition process. Capturing this level of detail in print form would probably have been impossible, even with an elaborate typographic code. So, while the encoding definitely required work and considerable persistence, I soon realized that it had real critical value for scholarship on the archival records of exploration (Fig. 5).

Kate: I agree that the technical learning curve was challenging not only in learning how to encode, but in knowing what to encode. Although my role in the digital edition of Missionary Travels was focused around the creation of a digital surrogate of the published book itself, prior to my work with you on that I had been involved with the transcription of the manuscript. It was only with the ease of comparison that the TEI facilitated that I was able to uncover quite how much that manuscript differed from the final published product and to see the mediated circumstances of the book's construction. But that ease had come at the expense of many, many hours spent working together to identify what needed to be encoded, how it needed to be encoded, and why. The TEI markup we have chosen means that users, among other things, can search for mentions of the same place throughout a corpus, even if that single place has been spelled different 


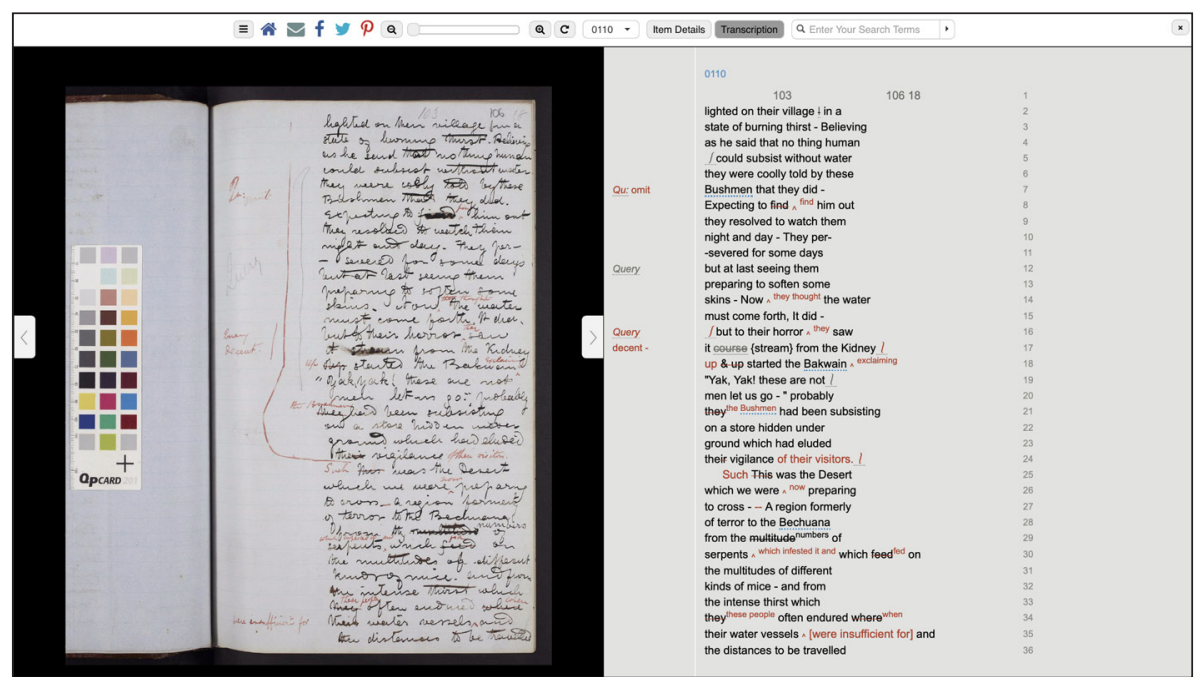

Fig. 5: Image of a page from the Missionary Travels manuscript (p. 110) accompanied by transcription, as displayed in the Livingstone Online manuscript viewer. (C) National Library of Scotland and Dr Neil Imray Livingstone Wilson (as relevant) CC BY-SA 2.5 UK: Scotland. This screenshot is representative of the manuscript details captured in transcription, such as textual corrections and annotations, and the modes of display used to represent them on-screen. The handwriting in red ink probably belongs to John Milton, a literary reviser employed by the publisher John Murray.

ways by multiple authors or if a single author has themselves spelled a single place in a variety of ways. I am incredibly aware of the responsibility we have in facilitating the text's afterlife and providing a bedrock for future research. But, I would like to know, were the challenges for you mainly technical or were there other sorts of challenges that you had not foreseen in beginning a digital humanities project?

Justin: Well, one thing is clear to anyone who has worked on digital projects: to succeed they require the involvement of multiple individuals with different expertise. These projects generally can't be accomplished through the work of just one person, and that was certainly my experience with the Missionary Travels edition. Shortly after deciding to embark on the project, it became clear that we would need a transcription and critical encoding team to get through the 1100 pages of manuscript. In the first place, this meant securing some funding and so led to various applications. Writing grant applications was a whole new area for me, but thankfully I had the infrastructural support of Livingstone Online and only needed fairly modest sums to get things going. In fact, the funding was generally incremental; over the next few years, the edition was supported by a series of small grants that covered particular phases of work. Once initial funding was in 
place, we were able to recruit a project team and start making progress. I was fortunate enough that some of the team members already had solid experience in this sort of work, including you [Kate] and Stephen [Hall], a recent $\mathrm{PhD}$ graduate from the University of Glasgow who had been an assistant on the Cullen Project. But managing a team was not something I'd done before, and I found coordinating the various tasks - like the process of transcription, critical encoding, review, and integration - as well as maintaining regular contact with multiple team members at any one time, to be quite difficult. In retrospect, the early stages of the project might have gone more smoothly with some more careful planning and had I given more attention to timetabling the work into clearly defined stages.

\section{Reflections on the project}

Adrian: Something I'd be interested to know about is the surprises that your work threw up along the way. Kate, in the various projects to which you've contributed - the two multispectral field diary projects, the final manuscripts, and the Missionary Travels manuscript - was there anything unexpected, any surprises that particularly struck you?

Kate: Going back to the source material is foundational to a lot of our own research, but, in looking so deeply and critically at the manuscript page itself as well as the words upon it in the process of encoding, I was awed by how tangible Livingstone and the environments he wrote in became. As I mention in my article on Livingstone Online, Livingstone's on-the-spot writings are valuable for that very reason - they are situated so close to the event that they hold the evidence of a series of narrative and situational variants. While in the nineteenth century, the published works and reported narratives of, and about, Livingstone had brought an awareness of previously distant cultures into English-speaking households, what they had also done was disambiguate or smooth the original idiosyncratic text. But, when you look through Livingstone's original manuscripts, he did much more than just provide the material which he would later use as an imperative to colonialism, western trade, and his own ambition. He identified the different people and places with which he came into contact. What Livingstone provided was hundreds of little bits of data about individuals with whom he interacted on the ground, and it was the depth, range, and quality of this information that struck me most forcibly.

Justin: In my case, research on the Missionary Travels manuscript led to at least two surprise findings about Livingstone and his book. First is the nature of the editorial changes that I was able to trace in the manuscript. It emerged that a lengthy section - running to thirty pages - in which 
Livingstone discusses the Cape Frontier Wars [the century-long series of border disputes between settlers and the amaXhosa in South Africa's Eastern Cape] had been redacted prior to publication. The views expressed in this passage are complex, but Livingstone's pointed criticisms of European settlers and his call to consider amaXhosa perspectives on the frontier conflicts are particularly notable. As I examined this section and other editorial changes to the manuscript, I realized that Missionary Travels was subject to a process of depoliticization in the journey from manuscript to book, in which politically contentious material was either tempered or removed. A second surprise was just how elaborate the book's composition turned out to be. Livingstone's correspondence with his publisher reveals a complex circulation of manuscript and print, in which galley proofs began to be distributed and revised early in the publication process even while new material was still being written. Alongside these simultaneous phases, moreover, Livingstone was also disseminating folios to trusted friends and the publisher's literary adviser for review and then making alterations in manuscript as necessary. This meant that he was working on multiple parts of the book - in both galley proofs and in manuscript - at any one time. The composition of Missionary Travels was both complicated and collaborative. It was interesting to learn too just how involved Livingstone's brother, Charles, was in the making of the book. This hadn't previously been appreciated, but we now know that Charles played a major role as an amanuensis since around 120 pages of the third manuscript volume are written in his hand.

Kate: Justin, do you think because this was to be a digital edition that you approached the primary material differently? If so, how did that feed into your research on Missionary Travels?

Justin: That's an interesting question. Well, I was drawn to focus on the manuscript of Missionary Travels rather than simply the published version of the book by a 'materialist' turn in scholarship on the literature of exploration. This scholarship emphasizes the importance of approaching works of travel as material objects that were shaped by practices of revision and redaction as well as the mediating influence of the publishing industry as they were prepared for print. To my mind, digital remediation facilitated and extended the materialist approach. In the first instance, the use of highquality images enabled the project team to scrutinize the manuscript more closely than would have been possible using only the physical documents without digital enhancement. The magnification of the manuscript was particularly useful when it came to reading cancelled text or deciphering instances of overwriting. But it was also important that the task of critical encoding demanded a careful delineation of the manuscript's characteristics. Markup in TEI enables the systematic description of the textual and 
structural features of a document, and Livingstone Online's customized coding practices, which include additional guidance for the Missionary Travels manuscript, fully avail of this capacity. Encoding the manuscript meant that particulars - like marginal annotations, interlinear additions, textual corrections implemented by various hands, and the recurrence of specific proof correction symbols - were consistently recorded. The result of this exercise was a cumulative picture of the inscriptive practices and editorial patterns that shaped Missionary Travels as it was readied for publication. Patterns like the sanitization of the book - as it was refined in accordance with the conventions of polite publishing and respectability - emerged much more clearly than they would have done otherwise. Put another way, undertaking the project using digital technologies really clarified the concerns of reception and literary propriety that were brought to bear on the book's production (Fig. 6). What about your experiences? Does working in the digital humanities make either of you think about Livingstone's writings and the record of exploration in new ways?

Kate: For me, the digital mediation of Livingstone's manuscripts has facilitated a critical translation of imperial power through the written word in surprisingly subversive ways. I would suggest that this is specifically enabled via the advantages that document encoding can bring to critical

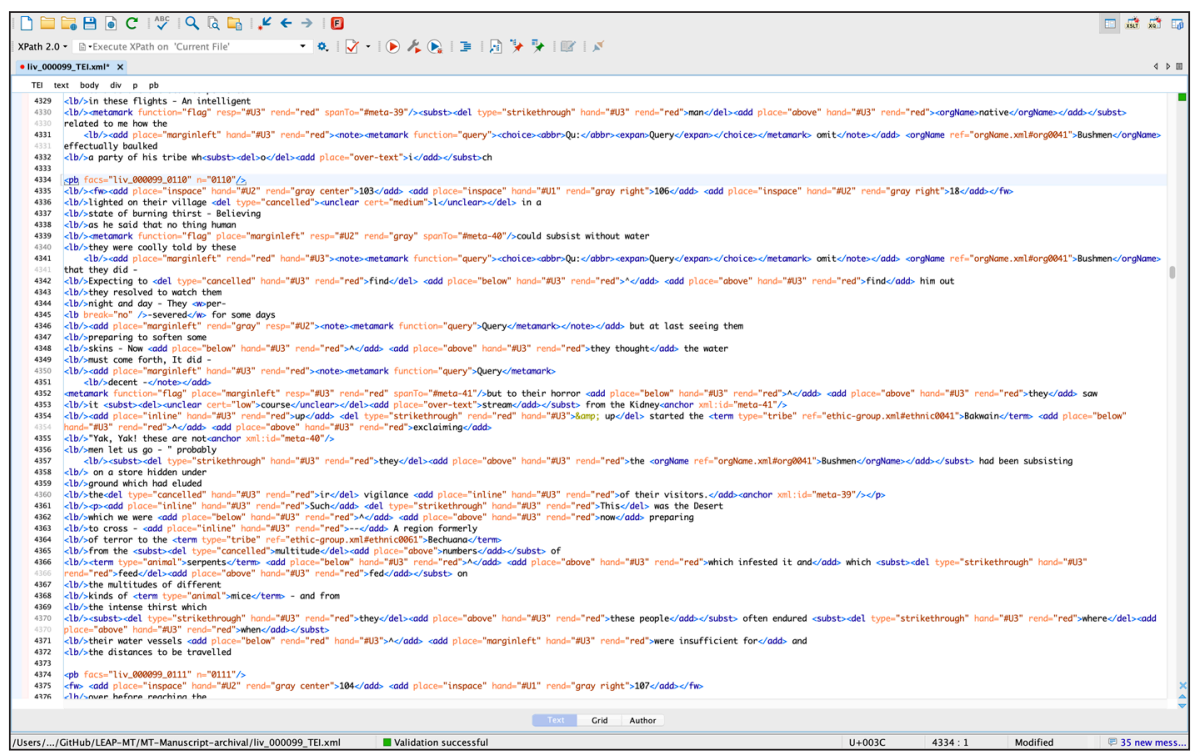

Fig. 6: Transcription of a page from the Missionary Travels manuscript, encoded in TEI P5. ( ) Livingstone Online CC BY-NC 3.o. This segment of TEI corresponds to the manuscript page and on-screen rendering shown in the previous image and displays some of the editorial markup and encoding practices developed by Livingstone Online. 
engagement with historical cultural documents. In my own work, that is in the intimacy with the texts and objects as data - pursuant on my ability to mine, play with, and pull apart Livingstone's diaries, journals, letters, and other manuscripts without losing the original meaning of the words and without changing the original author's intentions. I acknowledge the complexity and critical ambiguities of the texts and objects with which we deal and that we are unable to fully disarticulate our work from the colonial and imperial structures of power in which the works are embedded. But our work as a team at Livingstone Online, a form of socio-critical research, is rooted not only in the digital tools we use but in our emphasis on collaborative and interdisciplinary working which challenges us to question, review, and justify the critical and analytical actions we undertake. In nineteenth-century exploration publications African people were often 'othered', deindividualized, and made strange. The digital technologies and coding practices we adhere to at Livingstone Online have not only brought these people forward within the data, but they are also allowing the record of exploration to be contested, critiqued, and challenged in ways that allow for new interpretations and readings. Of particular interest for me has been mining Livingstone's texts for the many references to African women, references that have been ignored, or hidden in, to steal your prior phrase Justin, 'the sanitization of the book'. If the African male in the narrated European expeditionary space was the site of locomotive power, ambulation, porterage, geographical knowledge, gatekeeping, translation, acquisition, oppression, sociopolitical information store, and companionship, who or what is the African female by her unseenness? My current work explores this and asks how colonialism and gender define boundaries between seen and unseen and object and personhood in Livingstone's published and unpublished narratives. So, I think I can definitely say that working in the digital humanities has facilitated my research into critical renegotiations with records of nineteenth-century European exploration of Africa. Adrian, how about you?

Adrian: My experience has been similar to yours, and my ideas have evolved along similar lines. My work on Livingstone Online has always developed in the context of my original book project, Fieldwork of Empire. I started that project circa 2005, then finally published it in 2019, after we'd finished all of the major Livingstone Online editions and initiatives that I mentioned earlier. The development of the book's arguments about the influence that African contexts had on the production of British expeditionary literature significantly shaped my work on the site, particularly the emphasis on decentring Livingstone. At the same time, development of the site also determined how I wrote the book, especially the introduction, conclusion, and overall argumentative framework. In short, by working with an endless array of Livingstone manuscripts over a decade, I came to see that 
the experience of interacting with non-European individuals through the praxis of 'exploration' had an inescapable, all-encompassing impact on the texts that Livingstone and others produced in the field. I might be slightly exaggerating, but for me the idea of the single-authored expeditionary document now seems like the greatest myth promulgated by Victorian exploration culture. Livingstone's manuscripts are shot through with the traces of the field-based intercultural interaction and interlocutions that enabled him to write and do much of what he did. It's not silences in the archives that pervade, as critics often argue, but the abundance of voices and other non-European discursive and material influences. There are of course substantial challenges to studying these because textual representation itself is ultimately shaped by Livingstone. However, that's nothing to do with how the non-European contributions and influences infuse the pages of Livingstone's manuscripts. The real interpretive problem, I've now come to see, is how to foreground and otherwise critically remediate these contributions - in the many forms that the contributions take - so as to produce, inspire, and enable further scholarship. That's where my newest project, One More Voice [OMV], comes into the picture. OMV tackles this problem head on by identifying non-European contributions to the Victorian archive of exploration, defining what constitutes such contributions in the first place, and developing a methodology - it could be digital, analogue, or a combination, that's still to be determined - for recovering those contributions.

\section{Lessons learned from the project}

Adrian: I think we need to wrap up. Here's my last question. What's the biggest lesson learned from your work on Livingstone Online? For me, it's that I work best in collaboration. Through the project, I've developed a deep and lasting appreciation for how collective intellectual power, especially when it's rooted in collegiality, can solve even very challenging research problems. Working with people across disciplines also doesn't hurt because project colleagues in other disciplines often have amazing insights, ones that I never would have, and this is partly due to their disciplinary grounding. How about you both?

Kate: I think I have to agree with you, Adrian. The ability of collaborative working to make everyone involved and the project greater than the sum of their parts is incredible. The ease with which people adapt to working across disciplines and sharing knowledge is very heartening and will be nothing but valuable as we continue to use $\mathrm{DH}$ tools to record, renegotiate, and understand the impacts of colonial and imperial histories. 
Justin: Yes, this chimes with me too. I really valued the opportunity for sustained intellectual exchange. Conversations with the project team and with Adrian as joint director had significant influence on my approach to the Missionary Travels project as it progressed. But I'd also say that working on Livingstone Online drew my attention to just how much still remains to be done on the record of exploration. For one thing, the literary archives of other Victorian explorers haven't yet received anything like the attention given to Livingstone's writings. And I think that the approaches taken in Livingstone Online's many projects to correspondence, field notes, diaries, journals, and draft manuscripts highlight the scope that the digital humanities has for engaging with the material history and complicated production of travel records in their diverse forms. 